\title{
Environmental concerns and pollution control in the context of developing countries
}

\author{
Chih-Huang Weng ${ }^{1}$ \\ Published online: 15 July 2021 \\ (C) The Author(s), under exclusive licence to Springer-Verlag GmbH Germany, part of Springer Nature 2021
}

\section{Introduction}

In the developing countries, the pace of change - in vital technologies, in scientific research, in economic fundamentals, in the living environment, and in pursuing quality of life - is accelerating every day, propelled by continuous changes in technology innovation, human activities, and the rapidly evolving demands of the COVID-19 pandemic. This special issue (SI) of Environmental Science and Pollution Research (ESPR) collected 17 peer-reviewed articles relating to green buildings research, the impact of climate change on the extreme weather events, forward osmosis membranes for water reuse, the impacts of human activities to fragile water environments and economy, air pollution control and carbon emission reduction, risk assessment of pollution hazard and water resources, adsorption reaction of antibiotic pollution in subsurface, synthesized novel adsorptive materials in response to nitrogen and phosphorus, dye, and toluene pollution. All selected papers were relevance to the theme of this SI and formally presented at the 2020 th International Conference on Advances in Energy and Environment Research (ICAEER 2020) on September 18th-20th, 2020, Shanghai, China. For the safety of the participants, ICAEER 2020 was held via online presentation because of the coronavirus pandemic sweeping across all over the world. As an annually held conference, the upcoming 6th ICAEER 2021 is scheduled held in Shanghai from September 10 to 12, 2021 (http://www.icaeer.org/index.html). The guest editor (GE) of this SI welcomes you all to participate in this conference.

\section{Initiation}

The present SI was guest-edited by Professor Chih-Huang Weng (I-Shou University, Kaohsiung, Taiwan). The GE would like to express sincere gratitude to the support from the Shanghai University of Electric Power (SUEP), I-Shou University, and University of the West of England (UWE). Dr. Rohitha Weerasinghe (UWE) served as a Technical Program Chair is acknowledged. Particularly, the GE is grateful to Prof. Wu Jiang at SUEP for his tremendous supports on organizing local committees, providing conference venue, and acting as a chairperson of the conference. Special thanks are also due to Mr. Fengjie Cen for coordinating the ICAEER 2020 conference and Ms. Mandy Cen, the Conference Secretary, to make this SI published successfully. The GE is

Responsible Editor: Philippe Garrigues

Chih-Huang Weng

chweng@isu.edu.tw

1 Department of Civil Engineering, I-Shou University, Kaohsiung, Taiwan very grateful to Editor-in-Chief of ESPR, Prof. Philippe Garrigues, Editorial Assistant Ms. Florence Delavaud and Ms. Fanny Creusot for providing us an opportunity and support in publishing this SI. The GE thanks all the authors contributing valuable findings to this SI. Their works will further advance our knowledge to enable better understanding the environmental issues in the context of developing countries. Last but not least, the GE appreciates the handling editors and all the reviewers for their valuable and critical comments on the manuscripts that were submitted to this Special Issue.

\section{Highlights of selected papers}

The major findings of the papers included in this SI are highlighted as follows:

- Li et al. (2021a, b) conducted a global review of green building developments using bibliometric analysis on the basis of a collection of latest two decades researches. They explored emerging trends and hotspots researches on the subject of green building development and also suggested viable routes for future study. 
- To gain insight into the impacts of climate change on the extreme weather events and the vulnerability in Taipei, Taiwan, Lee and Lin (2021) studied the correlations between individual attributes and place attachment of residents in vary vulnerable areas in Taipei. They revealed that no consistent correlations between individual attributes and place attachment in areas with different vulnerabilities, also no factors could show a significantly relationship with overall place attachment.

- Technology for enhancing the performance of matrix forward osmosis (FO) membranes is now available. Zhang et al. (2021) fabricated the FO membranes that incorporated with $0.5 \%$ functionalized multiwalled carbon nanotube could largely improve the efficacy of FO when it exposed to solution containing different inorganic components and high ionic strength. An overall flux recovery rate greater than $85 \%$ for FO membranes was achieved.

- By combining with the real-time location of pollution sources, Yan et al. (2021) provided an algorithm to guide the population search while avoiding trapped into local optimal using a multi-strategy dynamic multi-mode optimization algorithm based on domain knowledge. The as proposed algorithm could effectively solve the issues of real-time location pollution sources in different pollution scenarios and pipeline networks.

- Human activities could have a profound effect on the water quality and hydrodynamics of a lake. Such effects have been exemplified by water level, flow field, and water quality of the Hongze Lake in response to changes in project operation, land use, and pollution accident via the simulation of 2D hydrodynamic model, hydrological model, and water quality models (Liu et al. 2021a, b).

- Li et al. (2021a, b) combined remote sensing and biomass data of the Lijiang River Basin (LRB) from 1995 to 2015 to assess the impacts of land use change on ecosystem service value (ESV) in this Karst basin. A decreasing trend of the overall ESV in the studied fragile ecological region was found. The authors indicated that an obvious change in land use could result in the changes of ecosystem services structure and a significant loss in ESV. The changes of ESV in the LRB also associated with population, GDP, and urbanization rate.

- Based on a selection of 218 Chinese polluting listed companies from year 2010-2018, Xiong and Luo (2021) revealed that the decision-making behavior of enterprises to address corporate social responsibility (CSR) is affected by smog. They concluded that the more serious the smog present, the more likely enterprises are to perform CSR and receive more media attention. Also, the media attention plays a vital role in moderating the interrelationship between CSR and smog.
- Wang and Zhang (2020) investigated the efficacy of particulate matter (PM), heavy metals, and dioxins from a typical sintering plant with both semi-dry and wet flue gas desulfurization (FGD). They found that the removal efficiency of both PM and heavy metals ( $\mathrm{Pb}, \mathrm{Cr}$, and $\mathrm{Zn}$ ) from the wet FGDs was slightly better than the semi-dry FGDs. The overall dioxins removal efficiencies from both FGDs were around $36 \%$, but the polychlorinated dibenzofurans ratio in the dioxins showed drastically decrease from 80.83 to $44.35 \%$ in semi-dry FGD.

- Recognizing the importance of mercury pollution in coalbased combustion, Liu et al. (2021a, b) highlight the catalytic effects of high iron and calcium coal ash (HICCA) on $\mathrm{Hg}^{0}$ removal and its impact of gas impurities in a looping combustion process. The authors found that the presence of $\mathrm{HCl}$ and $\mathrm{NO}$ significantly improved $\mathrm{Hg}^{0}$ removal while $\mathrm{SO}_{2}$ exhibited an inhibitory effect. The authors also proposed reaction mechanisms of $\mathrm{HCl}, \mathrm{NO}$, and $\mathrm{SO}_{2}$ with the HICCA.

- On the basis of panel data from thirty provinces (China) during year 2005 to 2016, Cai et al. (2021) used a carbon emission expansion model and a nonlinear threshold regression model to analyze the threshold effect of outward foreign direct investment (OFDI) and inward foreign direct investment (IFDI) on the emission intensity of $\mathrm{CO}_{2}$ in China. They concluded that OFDI has increased carbon dioxide emission intensity while IFDI exhibited a significant inhibitory effect, suggestion that

China should optimize its OFDI structure, impose more IFDI, and couple with the exerting of environmental improvements as a whole to insure satisfying the goal of carbon emission reduction.

- Based on the POOL model and a full-scale model of liquid chlorine tanks, Xin et al. (2021) successfully established the dynamic characteristics of chlorine dispersion behavior upon liquid chlorine releasing from tanks within a radius range of three kilometers. Also, the social risk and individual risk was determined quantitatively. They found that leakage of chlorine happens in three stages, i.e., dynamic dispersion, gravity dispersion, and atmospheric dispersion.

- Shi et al. (2021) applied the backpropagation artificial neural network (BP-ANN) model to develop method for analyzing the cumulative risks to the water environment. By employing a collection of cumulative risk indexes and data concerning evaluating indicators of the Liao River from 2005 to 2017 for training, validating, and testing the BP-ANN model, they found that such assessment approach is robustness and applicable to cumulative risks assessment of water environment.

- By employing geographic information systems and ex- 
ploratory spatial data analysis methods with industriallevel panel data over the period of 1997 to 2018, Chen and Chen (2021) identified the spatiotemporal relations between industrial wastewater discharge and industrial economy in China.

- Wei et al. (2021) used levofloxacin (LVFX) as a surrogate of the fluoroquinolone antibiotics to evaluate the fate of LVFX in the vadose zone. They found that adsorption was the main reaction governing the retention LVFX in silty clay. Based on the simulation of Hydrus-1D transport model, the groundwater was potentially contaminated by LVFX after about one month.

- Fu et al. (2021) successfully modified water treatment residuals-sodium alginate beads (WTR-SA beads) that could effectively remove $\mathrm{N}$ and $\mathrm{P}$ from wastewater. The key mechanisms responsible for adsorption of $\mathrm{N}$ and $\mathrm{P}$ onto the modified WTR-SA beads were proposed.

- Guan et al. (2021) successfully synthesized glass fibers from waste-printed circuit board as a support of MIL100(Fe) (GFS/MIL-100(Fe)) for effective adsorptive removal of some textile dyes, including rhodamine $\mathrm{B}$, malachite green, acid orange 7 , and methylene blue, from aqueous solution. The as-synthesized novel GFS/MIL$100(\mathrm{Fe})$ was reusable and it still maintained a satisfactory dye removal efficiency even after a three-time reuse.

- Wang et al. (2021) showed that activated carbon made by corn bran with microbial pretreatment (Trichoderma viride) could boost its specific surface area and total pore volume as high as $1896 \mathrm{~m}^{2} / \mathrm{g}$ and $1.04 \mathrm{~cm}^{3} / \mathrm{g}$, respectively. Such porous carbon material is idea for adsorptive VOCs removal, particular for toluene.

\section{Declarations}

Conflict of interest The author declares no competing interests.

\section{References}

Cai L, Firdousi SF, Li C, Luo Y (2021) Inward foreign direct investment, outward foreign direct investment, and carbon dioxide emission intensity-threshold regression analysis based on interprovincial panel data. Environ Sci Pollut Res https://doi.org/10.1007/s11356-02011909-3

Chen M, Chen H (2021) Spatio-temporal coupling measurement of industrial wastewater discharge and industrial economy in China. Environ Sci Pollut Res. (Accepted 31 May 2021)

Fu G, Zhao Y, Zhou S, Chen C, Zhong Y, Xu Y (2021) Efficient removal of nitrogen and phosphorus in aqueous solutions using modified water treatment residuals-sodium alginate beads. Environ Sci Pollut Res. https://doi.org/10.1007/s11356-021-12586-6
Guan C, Tao Y, Chen S, Zhu J, Gao X (2021) Synthesis of glass fiber sphere using waste printed circuit board to support MIL-100(Fe) for dye adsorption in water. Environ Sci Pollut Res. https://doi.org/10. 1007/s11356-021-13814-9

Lee YJ, Lin SY (2021) A study on the relationships of place attachment and individual attributes of residents in different vulnerable districts in Taipei, Taiwan. Environ Sci Pollut Res. https://doi.org/10.1007/ s11356-021-13416-5

Li N, Wang J, Wang H, Fu B, Chen H, He W (2021a) Impacts of land use change on ecosystem service value in Lijiang River Basin, China. Environ Sci Pollut Res. https://doi.org/10.1007/s11356-020-121900

Li Y, Rong Y, Ahmad UM, Wang X, Zuo J, Mao G (2021b) A comprehensive review on green buildings research: bibliometric analysis during 1998-2018. Environ Sci Pollut Res. https://doi.org/10. 1007/s11356-021-12739-7

Liu B, Cai S, Wang H, Cui C, Cao X (2021a) Hydrodynamics and water quality of the Hongze Lake in response to human activities. Environ Sci Pollut Res. https://doi.org/10.1007/s11356-021-12960-4

Liu Z, Liu D, Jin J, Feng L, Ni M, Zhao B, Wu X (2021b) Impact of gas impurities on the $\mathrm{Hg}^{0}$ oxidation on high iron and calcium coal ash for chemical looping combustion. Environ Sci Pollut Res. https:// doi.org/10.1007/s11356-020-11872-Z

Shi E, Shang Y, Li Y, Zhang M (2021) A cumulative-risk assessment method based on an artificial neural network model for the water environment. Environ Sci Pollut Res. https://doi.org/10.1007/ s11356-021-12540-6

Wang H, Zhang P (2020) Emission characteristics of PM, heavy metals, and dioxins in flue gases from sintering machines with wet and semi-dry flue gas desulfurization systems. Environ Sci Pollut Res. https://doi.org/10.1007/s11356-020-11500-w

Wang X, Cheng H, Ye G, Yao F, Wang Y, Jiao Y, Zhu W, Huang H, Ye D (2021) Preparation of porous carbon based on partially degraded raw biomass by Trichoderma viride to optimize its toluene adsorption performance. Environ Sci Pollut Res. https://doi.org/10.1007/ s11356-021-12796-y

Wei M, Lv D, Cao L, Zhou K, Jiang K (2021) Adsorption behaviours and transfer simulation of levofloxacin in silty clay. Environ Sci Pollut Res. https://doi.org/10.1007/s11356-021-13955-x

Xin B, Yu J, Dang W, Wan L (2021) Dynamic characteristics of chlorine dispersion process and quantitative risk assessment of pollution hazard. Environ Sci Pollut Res. https://doi.org/10.1007/s11356-02011864-Z

Xiong G, Luo Y (2021) Smog, media attention, and corporate social responsibility - empirical evidence from Chinese polluting listed companies. Environ Sci Pollut Res. https://doi.org/10.1007/ s11356-020-11978-4

Yan X, Zhou Z, Hu C, Gong W (2021) Real-time location algorithms of drinking water pollution sources based on domain knowledge. Environ Sci Pollut Res. https://doi.org/10.1007/s11356-02113352-4

Zhang H, Wang X, Wang L, Lv Y, Zhang Z, Wang H (2021) Identifying the fouling behavior of forward osmosis membranes exposed to different inorganic components with high ionic strength. Environ Sci Pollut Res. https://doi.org/10.1007/s11356-021-14170-4

Publisher's note Springer Nature remains neutral with regard to jurisdictional claims in published maps and institutional affiliations. 


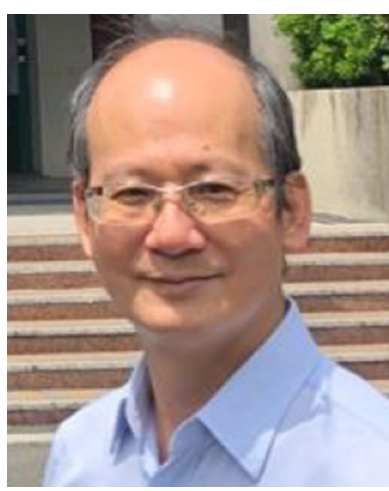

Dr. Chih-Huang Weng is a Full Professor in the Department of Civil Engineering at I-Shou University, Taiwan. He also served as vice president of North Kaohsiung Community University, Taiwan. He received his MS and Ph.D. degrees in 1990 and 1994, respectively, from the Department of Civil Engineering of The University of Delaware, USA. He has published over 100 journal articles with 6427 citations, $41 \mathrm{~h}$-index and 75 i10-index in google scholar database. Based on the 2020 updated science-wide author databases of standardized citation indicators (https://journals.plos.org/plosbiology/ article id $=10.1371$ /journal.pbio.3000918), his publication citation was listed on the top $1 \%$ and ranked at 263rd among 42,482 authors in the category of Engineering, Environmental. He has earned number of awards and honors, including the National Innovation Award by the Research Center for Biotechnology and Medicine Policy, Taiwan. He is serving as the Associate Editor of Environmental Geochemistry and Health (Springer, since 2020) and on the Editorial Board Panel Member of Coloration Technology (Wiley, since 2013). He has also served as a Guest Editor of journals, such as Agricultural Water Management (Vol. 174, Aug. 2016, Elsevier) and Environmental Science and Pollution Research (Vol. 26, issue 30, Oct. 2019; Vol. 27, issue 31, Oct. 2020, Springer). He has also organized and chaired several international conferences. His main research interests focus on using advanced oxidation processes and adsorption for the treatment of wastewater and bacteria inactivation, ground water modeling, and application of electrokinetic technologies to soil remediation/sludge treatment/activated carbon regeneration. 